\title{
Innovative Models Proposals for the Implementation of Adaptive Hypermedia Systems
}

\author{
Mehdi TMIMI ${ }^{1}$, Mohamed BENSLIMANE ${ }^{2}$,Mohammed BERRADA ${ }^{3}$ and Kamar \\ OUAZZANI $^{4}$ \\ \{mehdi.tmimi@usmba.ac.ma ${ }^{1}$, benslimane_mohamed@live.fr ${ }^{2}$, \\ mohammed.berrada@gmail.com ${ }^{3}$ kamar_ouazzani@yahoo.fr ${ }^{4}$ \} \\ Laboratory of computing and interdisciplinary physics, ENS, USMBA, Fez, Morocco ${ }^{134}$ \\ Transmission and Treatment of Information Laboratory, EST, USMBA, Fez, Morocco ${ }^{2}$
}

\begin{abstract}
This article is the continuation of our work concerning the development of an adaptive hypermedia system. In previous work, we proposed three new fundamental models for the implementation of an adaptive hypermedia system. such as: learner model, domain model and adaptation model. The purpose of this article can be summarized first by presenting our three proposed models while discussing the related work that we have studied and the new ideas that we have invented and implemented, and then the development of the global architecture of our future adaptive hypermedia that we intend to present it in details in future work.
\end{abstract}

Keywords: Adaptive Hypermedia Systems, Learner Model, Adaptation Model, Domain Model, E-learning, SCORM, CMI5, MUNICH, AHAM, ALEM.

\section{Introduction}

The brain is immensely complex to the point that until now it represents a mystery for researchers and scientists. This complexity involves also the learning process which is one of the main functions of the brain. Learning is defined as a relatively permanent change in knowledge and skills resulting from experiences. Indeed, we have found in literature several learning methods, namely: Learning by imitation [1], associative learning [2], learning by trial and error [3], observational learning, learning by repetition, etc. All of these methods are present in both traditional (classic) and distant learning (E-learning).

The first type of learning refers to the classical method where there is a teacher who brings together several learners in a class, or amphitheater. While the second type describes the new method of learning that unlike the classical one does not have constraints of time and place. Nowadays this new type of learning is known as E-learning which in collaboration with technological progress and internet has successfully challenged and remedied the major problems of classical learning. 
In literature, the distant learning has an old history of almost three centuries that can be summed up in three eras [4]:

1. First era: learning by correspondence.

2. Second era: learning using radio and television

3. Third era (E-learning): learning using the Internet and new multimedia technologies.

The European Commission has defined the E-learning as "the use of new multimedia technologies and the Internet to improve the quality of learning by facilitating access to resources and services as well as and remote collaboration ". [5]

Given the success of this new type of learning, many systems and approaches have taken the step towards online learning and have dominated distance learning in recent years. However, these systems and approaches are today considered 'traditional' because on the one hand, they do not respect the technological progress of Internet, and on the other hand they are based on the tradition of "one design for all" [6] where the same course with the same structure and presentation is delivered to all types of learners.

As a result, a new generation of e-learning systems has emerged, known as adaptive learning systems, which gives learners an active role in acquiring knowledge and skills while also adapting the content of learning according to theirs needs and preferences.

These adaptive learning systems have a minimal architecture generally composed of three interdependent models. Which are:

1. Learner model: describes learner characteristics such as: skills, knowledge and learning styles, etc. [7]

2. Adaptation model: describes the set of construction and presentation rules that are responsible for constructing the content to be provided to the learner.

3. Domain model: describes the structure of the information content of the application [8]. Since the main objective of our research is the design and development of an adaptive hypermedia system, we will present in this article all the three fundamental models that we have developed while discussing the related work we have studied and the new ideas that we invented and implemented.

\section{Learner model}

The learner model is a very promising solution for representing and describing information about a learner, in order to provide a complete and faithful description of all aspects related to the learner's behavior in the learning phase.

In our previous work [9], we proposed the basic elements of our new learner model that we deduced from a set of existing approaches and ontologies. Our proposal for the learning model is based on six facets, which are:

- Personal information: represents the personal data of the learner, namely his identity, sex, age, etc.

- Knowledge and skills: contains all the knowledge, skills, and competencies of the learner.

- History: This facet is responsible for saving all the actions and interactions of the learner within the adaptive hypermedia.

- Psychological profile: Represents the learner's preferences and psychological

profile. it is so often based on one of the psychological types theories. 
- Cognitive ability: refers to all specialized treatments that require the collaboration of brain spaces. Such as: attention, memory and strategies, vision, space, language, gestures and coordination.

- Emotional state: represents the emotions experienced by the learner during the learning phase. Such as: frustration, satisfaction, etc.

These facets were the subject of a detailed study published in a previous work [10] where we first presented our research made on each one of the six facets and then proposed our own learner model shown in Figure 1.

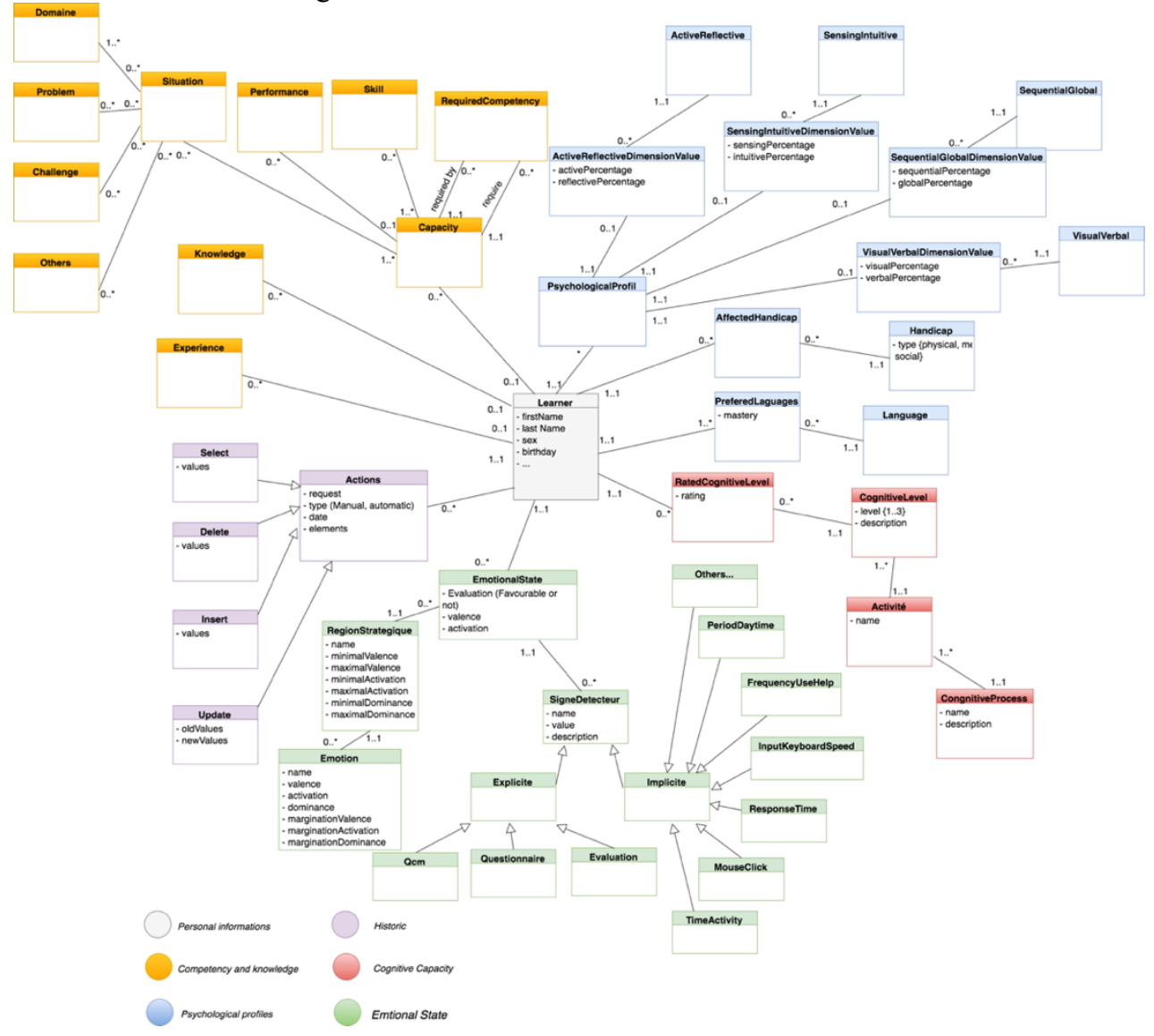

Fig. 1. Proposed learner model [10]

\section{Domain model}

The domain model describes the structure of the course elements such as: knowledge, concepts, etc. And also describes the resources needed to present its elements. Namely: videos, articles, homework, questionnaires [11], etc. 
To develop this model, we first studied the reference models for adaptive hypermedia: AHAM [12] and MUNICH [13] and then the online learning technical standards such as SCORM [14] and CMI5 [15].

Regarding The domain model proposed by the two reference models AHAM and MUNICH. We've found that their domain model describes the structure of hypermedia as a collection of connected components, which form a network expressed by the composite design pattern [16]. Typically, a component is an abstract representation of concepts (knowledge, information, exercise, etc.), concepts relationships, pages and fragments.

However, we have deduced several remarks that can be resumed mainly first in the lack of semantics which refer to the objective or goal behind learning a concept and secondly in the type of architecture that they used, which we described it as a content-oriented architecture. This architecture is mainly built around the content (component).

Before discussing the online learning technical standards such as SCORM and CMI5. We need to shortly introduce them.

So, The Shareable Content Object Reference Model (SCORM) is a set of technical standards for e-learning software products developed by ADL (Advanced Distributed Learning [17]). It was mainly designed to present a reference model for defining and constructing learning course content that have the capacity to be shared with other SCORM compliant systems.

Unlike SCORM, CMI5 was not exclusively developed by ADL. Indeed, CMI5 was codeveloped by both ADL and the Aviation Industry Computer-Based Training Committee (AICC). CMI5 intended to take advantage of both SCORM and Experience API (xApi) while responding for their limitations and adding some new capabilities.

These two online learning technical standards was the focus of our research where we first studied their specifications and then designed their UML class diagrams. these conceptual representations allowed us to notice that SCORM and CMI5 are based too on a content-oriented structure and were intentionally only designed to deliver content to a learner (traditional elearning system).

Finally, after this analytical and critical study, we designed a new domain model - shown in Figure 2 - that responds to all the criticisms cited above. 


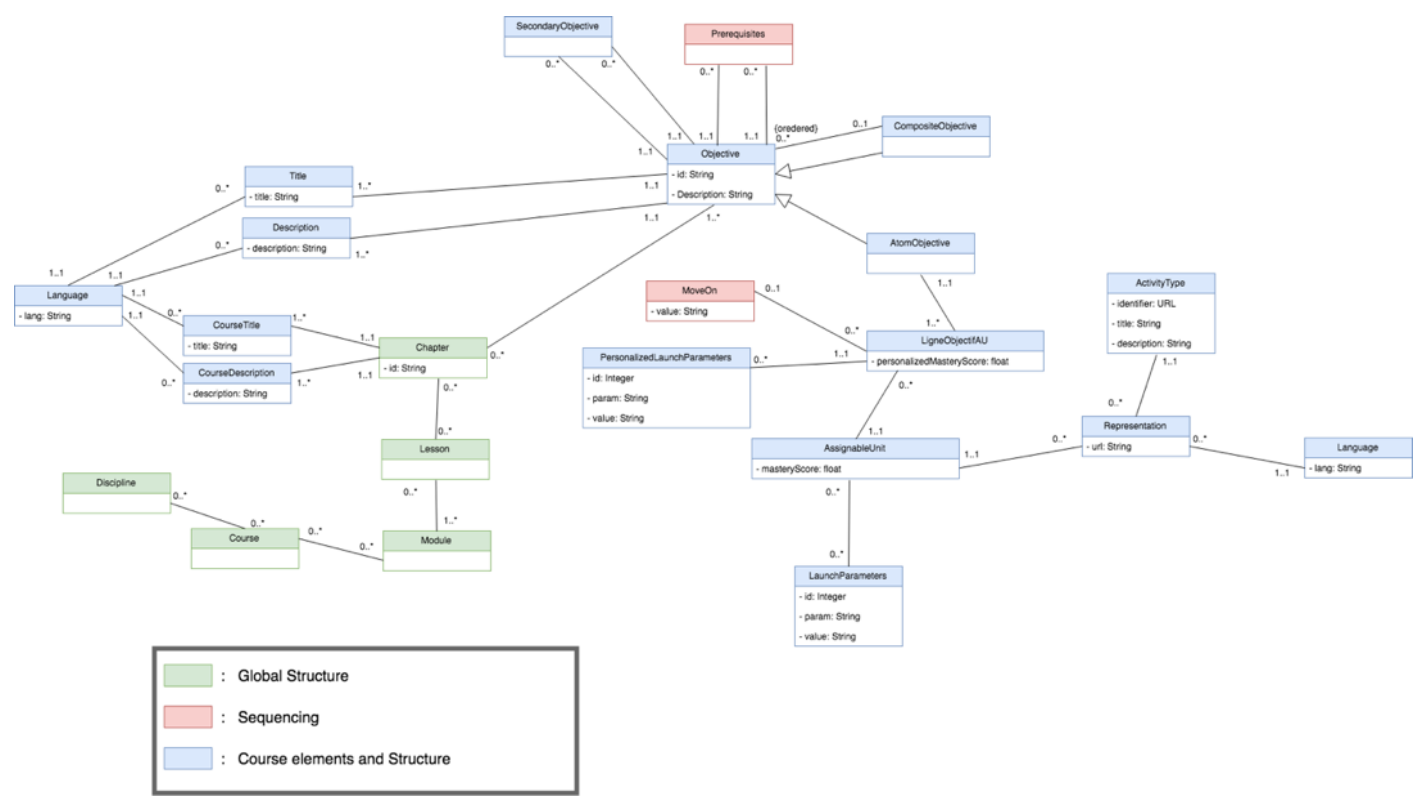

Fig. 2. Proposed domain model

\section{Adaptation model}

The adaptation model represents the mechanisms responsible for customizing and adapting learning content, links, representation and the structure of concepts and knowledge to be delivered to learners.

Indeed, there are several aspects that the adaptation and the personalization can be carried out. Which are:

Link adaptation: it concerns the management of the links by allowing either to limit the possibilities of navigation in the hypermedia, or to offer to the learner new links leading to other concepts.

Content adaptation: this type of adaptation concerns the selection of the most suitable and appropriate content to be delivered to the learner.

Structure adaptation: allows to display the same content under several structures and in different forms.

Adaptation of the presentation: this type of adaptation concerns the display of the same content of the page in different custom styles according to the learner's preferences. Such as: font weight, color, etc.

So, in a similar way to the learner and domain model, we studied the existing adaptation models proposed by MUNICH and ALEM [18].

\subsection{MUNICH}


In Figure 3, we present the UML class diagram of the adaptation meta-model proposed by Munich that mainly constructed around the 'Adaptation' and 'Rule' classes.

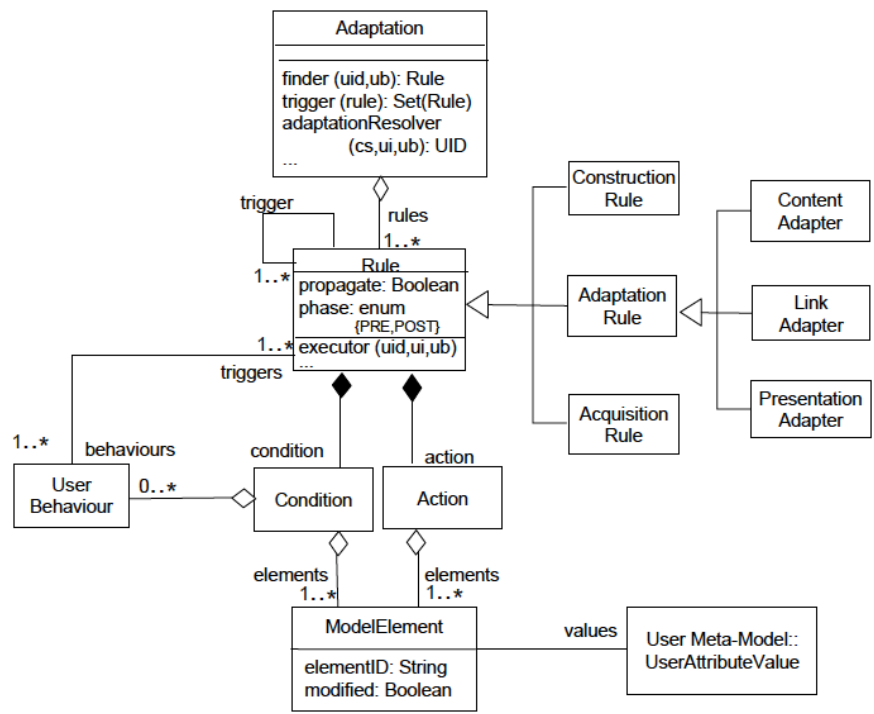

Fig. 3. Adaptation meta-model proposed by MUNICH [13]

The Adaptation class consists of three methods: an adaptation resolver, a finder, and a trigger. The first method resolves the specification of a component to a suitable component. The second and third methods implement a mechanism that finds all the rules that must be triggered by a given rule. The first rule to use is triggered by the user's behavior. The executor method of the 'Rule' class allows the system to select the appropriate components and to adapt the content, layout and link, as well as update the learning model.

Each object of class 'Rule' contains attributes and many conditions and actions related to it by the mean of a composition relation. The attributes refer to several pieces of information used for determining whether the rules are applied before or after updating the learning model.

Finally, the rules 'class Rule' are classified according to their mode of intervention in four types: rules of construction, rules of acquisition and rules of adaptation. This distribution is expressed by means of the inheritance mechanism provided by the UML class diagram.

\subsection{ALEM}

As shown in Figure 4, the adaptation model proposed ALEM is designed in a similar way to MUNICH. Indeed, ALEM is designed using the UML class diagram and built mainly around the Rule "Règle" class. 


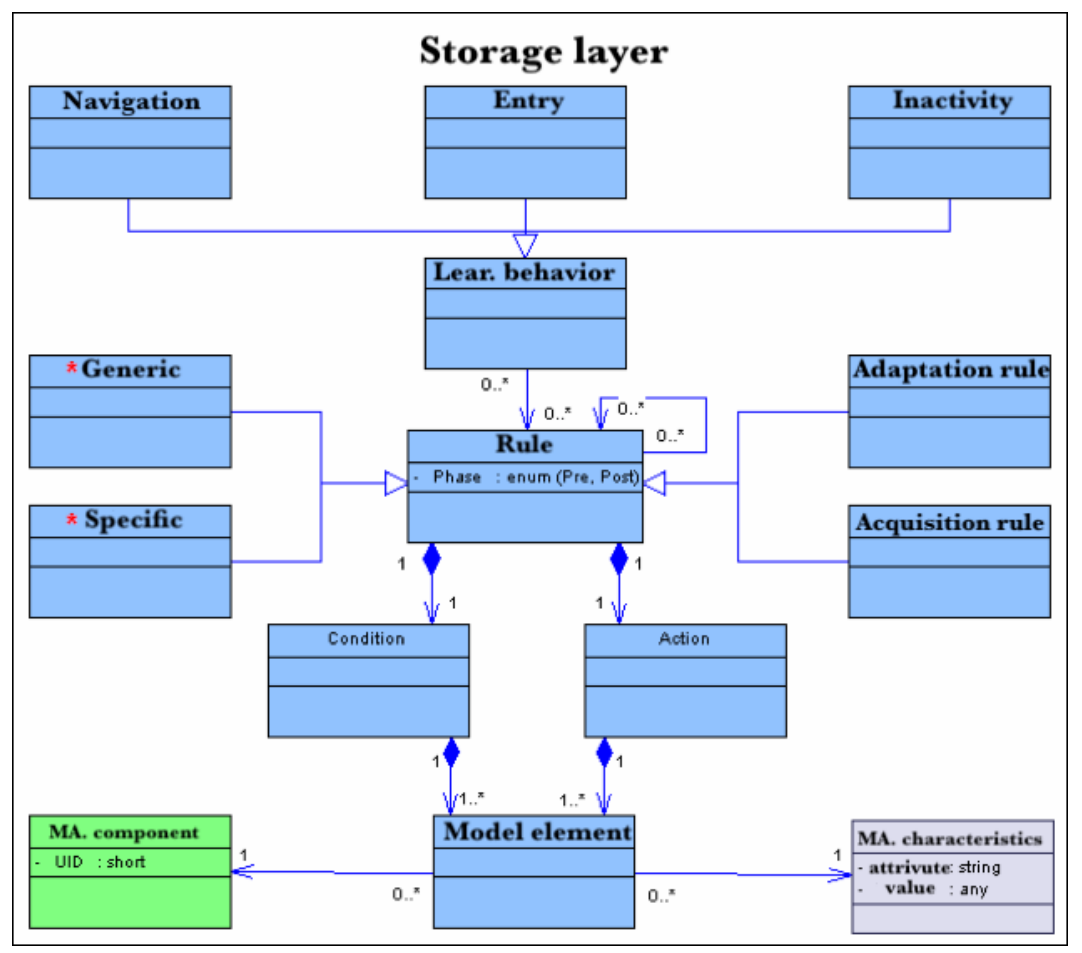

Fig. 4. adaptation meta-model proposed by ALEM [18]

However, in addition to most of the element supported by MUNICH, ALEM implemented a new concept for the adaptation rules expressed by the two classes:

- Generic rule "générique": refers to adaptive rules predefined by the designer of adaptive hypermedia.

- Specific rule "spécifique": this type of rule concerns the new rules created by the tutors and the authors of the learning content.

Finally, we noticed that learner behaviors are also introduced into the adaptation meta model and are classified into three classes: Navigation, Entry and Inactivity.

\subsection{Remarks and reproaches}

In the two proposed adaptation model by MUNICH and ALEM, we found several remarks and reproaches that make the proposed models incomplete or really difficult to implement. Indeed, although there are 4 types of adaptation that have different characteristics and levels of intervention, the two models (Munich and ALEM) have just included these 4 types of adaptation at the same conceptual level and in the same way without indicating how to implement and how to use them for adaptation. Also, ALEM assumes that each object of the class 'Rule' can refer to several types of rules namely: adaptation rule, acquisition rule, generic rule and specific rule. With the design shown in Figure 4, it's forbidden to have a rule that combines two types at a time. Example: an adaptation rule can not be also a generic rule. 


\subsection{Proposition}

Following the criticisms and reproaches cited above, we first developed a new adaptation model (presented in Figure 5) and then we implemented and tested it in a web platform.

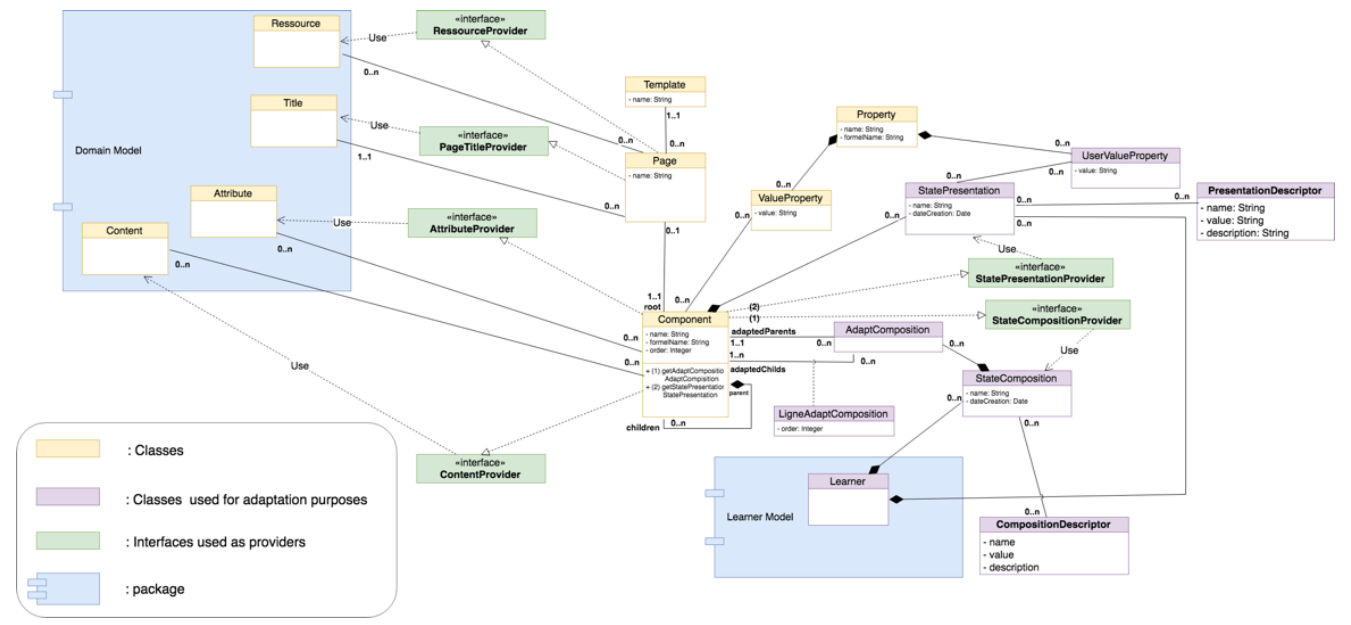

Fig. 5. Proposed adaptation model

\subsection{Teste and implementations}

In order to use our proposed model, we have developed a set of tools (see Figure 6 and 7) allowing the exploitation of the model and affirming its validity. The detailed description of these tools can be found in our published article [19].

- Tool for creating template pages:

Given the complexity of our proposed model and the need to respect its recommendations by the pages. we have developed a creation tool that takes on all the complexity and allows tutors to create pages that respect the structure proposed by our adaptation model

In figure 6 , we show the web tool that we have developed and that allow the creation of pages in real time, the following is a short list of the functionality supported by our tool:

- Component management.

- Component Presentation management

- Preview of the built page 


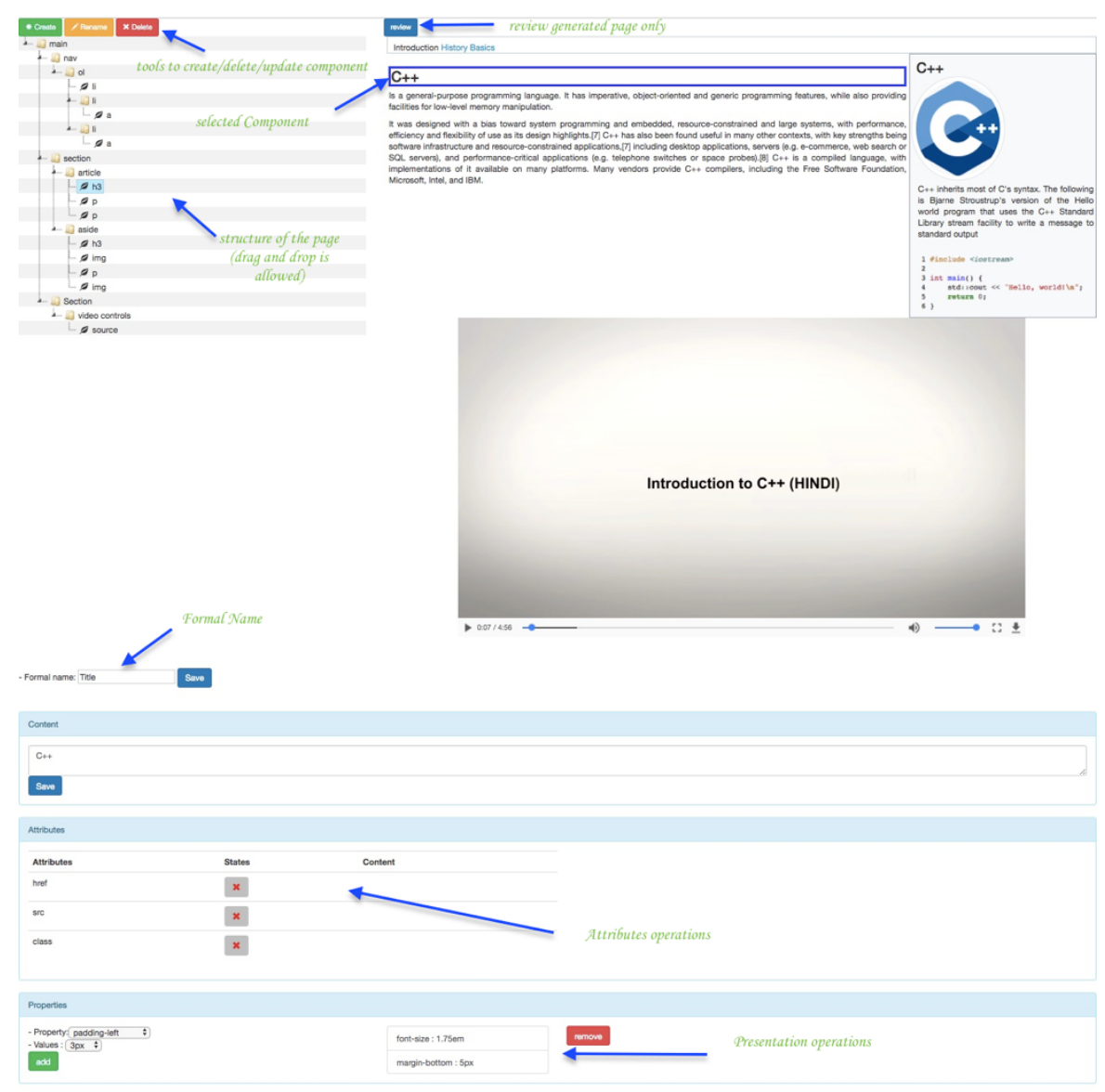

Fig. 6. Screenshot of our web app that represents the tools to create template pages

- Tool for Adaptation and customization:

In Figure 7, the system generates the built page to the learner while offering mechanisms for adaptation of structure and representation. In Figure 7 , both the original structure and presentation have changed, this new structure (the video is on the top of the page) is only applicable to this learner. 


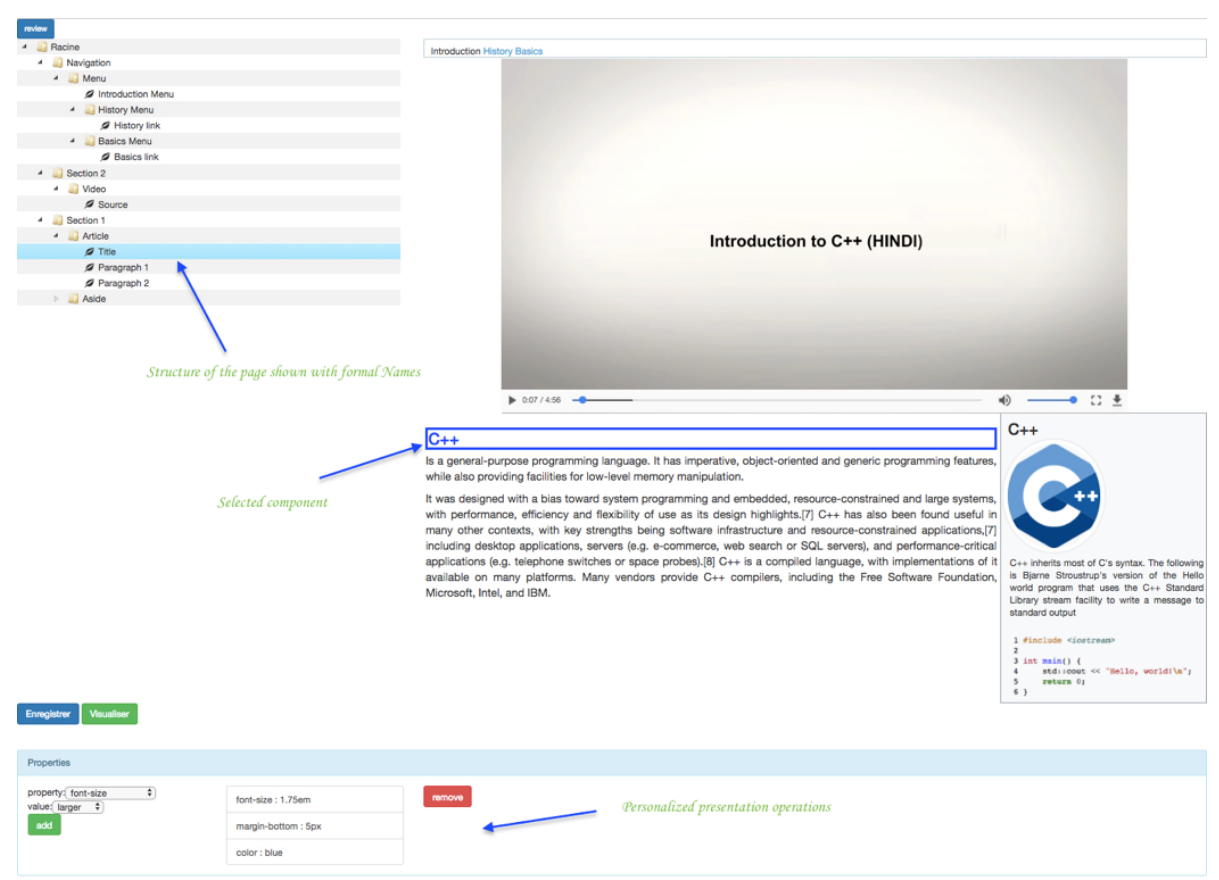

Fig. 7. Screenshot of our web app that represents a custom and adapted page of a learner

\section{Global architecture}

The three models we have developed form the core of our adaptive hypermedia system that we want to develop in the near future. Indeed, we have developed its global architecture (shown in figure 8) using the JEE design pattern and composed of our three models elaborated and other processes and engines required for its operation. 


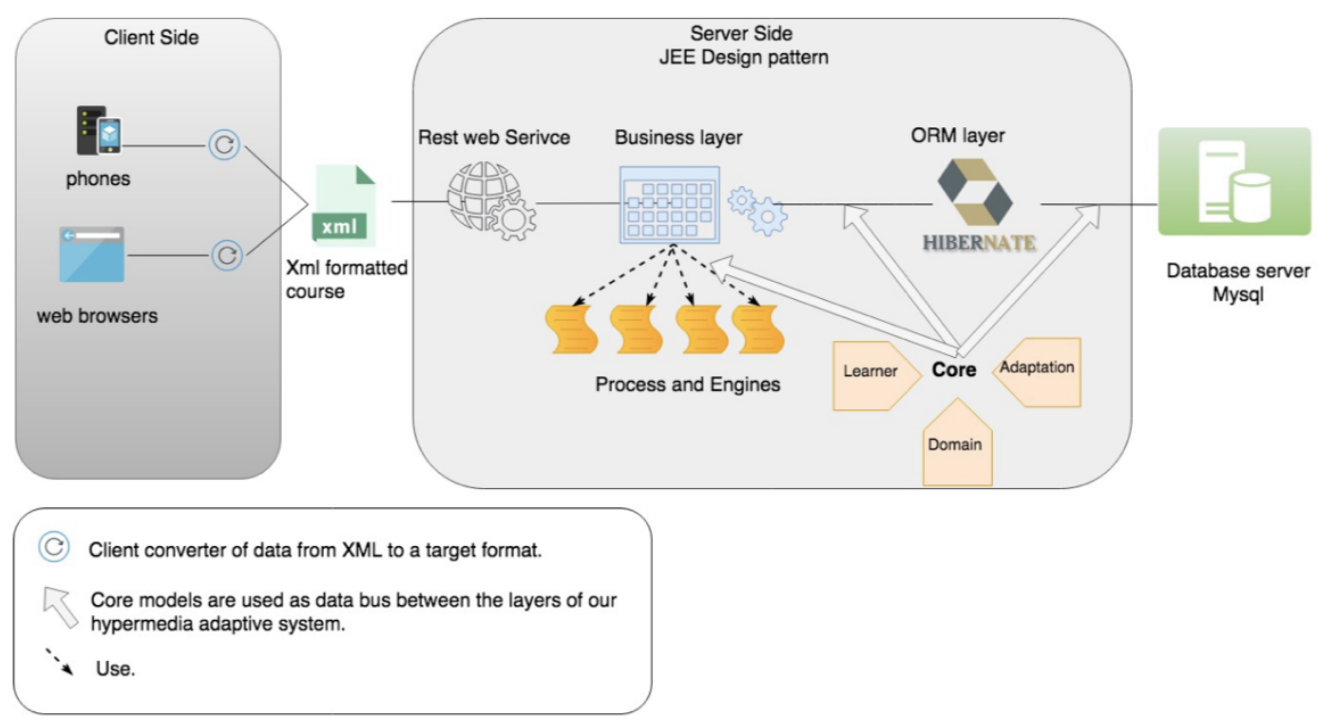

Fig. 8. Global architecture of our adaptive hypermedia system

\section{Conclusion and perspectives}

In this paper we presented our three designed models that represent the fundamental and indispensable elements for the development of an adaptive hypermedia. Indeed, in a future work we will first work on interconnecting these three models, then explain the conceptual and technological choices that we will use to implement the global architecture of our adaptive hypermedia system.

\section{References}

[1] F. Borsali: Apprentissage par observation chez le jeune enfant avec autisme. Psychologie. Université Paul Valéry - Montpellier III. Français. 〈NNT : 2015MON30022〉. Doctoral thesis (2015).

[2] J. Favrel: Psychologie des apprentissages, approches cognitive et comportementale. Université de Bourgogne, L2 EFEC. (2018)

[3] H. E. Gendolla: Behaviorisme IIa, Le conditionnement opérant I, "Motivation et apprentissage VII", Université de GENÈVE. [Online] available at: http://tecfaetu.unige.ch/etumaltt/volt/venni6/bases/2/7 behaviorisme IIa(1).pdf

[4] W.Wright, C. Jeffs, J. Wood: Distance Education : Must it be ' Out-of-Sight , Out-of- Mind' Education ?. available at: http://www.ascilite.org/conferences/melbourne95/smtu/papers/wright.pdf

[5] Commission of the European Communities: Communication from the Commission to the Council and the European Parliament - e-Learning Action Plan - Thinking about tomorrow's education.

Bruxelles, Brussels,COM(2001)172 final. (2001) available at : https://eur-

lex.europa.eu/LexUriServ/LexUriServ.do?uri=COM:2001:0172:FIN:EN:PDF 
[6] G. Kaya and A. Altun: A Learner Model for Learning Object Based Personalized Learning Environments. Commun. Comput. Inf. Sci., vol. 240, pp. 349-355. (2011).

[7] S. Drissi, T. Bensebaa, Y. Lafifi: Une nouvelle approche pour l'adaptation d'un hypermédia pédagogique au profil cognitif de l'apprenant en utilisant XML. in 2nd Conférence Internationale sur l'Informatique et ses Applications (CIIA'09). (2009).

[8] H. Wu, G.J.P.M. Houben, P. De Bra : Supporting user adaptation in adaptive hypermedia applications. Proceedings Conferentie Informatiewetenschap 2000,pp. 88-98.(2000)

[9] M. Tmimi, M. Benslimane, M. Berrada, K. Ouazzani: Elaboration d'une ontologie apprenant pour les hypermédias adaptatifs. Conférence Internationale sur les Approches Pédagogiques \& E-Learning, Morocco, Appel'2016. (2016).

[10] M. Tmimi, M. Benslimane, M. Berrada, K. Ouazzani: International Journal of Applied Engineering Research ISSN 0973-4562 Volume 12, Number 24, pp. 16008-16016. (2017)

[11] M. Madaio: Adaptive Learning Systems the State of the Field. in C21U Seminar, UnConference Room at C21U. (2015)

[12] P. De Bra, G.-J. Houben, H. Wu: AHAM, A Dexter-based Reference Model for Adaptive Hypermedia. in tenth ACM Conference on Hypertext and hypermedia: returning to our diverse roots: returning to our diverse roots, pp. 147-156. (1999).

[13] N. Koch, M. Wirsing: The Munich Reference Model for Adaptive Hypermedia Applications An Overview of the Reference Model. in 2nd International Conference on Adaptive Hypermedia and Adaptive Web-based Systems, pp. 213-222. (2002).

[14] Rustici Software: What is SCORM? [Online]. Available at: http://www.scorm.com/scormexplained/

[15] E. Cohen: cmi5 Specification Profile for xAPI. AICC. (2016) [Online]. available at: https://github.com/AICC/CMI-5 Spec Current/blob/quartz/cmi5 spec.md

[16] T. Sellarès: Composite Pattern. Universitat de Girona. Available at: http://ima.udg.edu/ sellares/EINF-ES1/CompositeToni.pdf

[17] ADL: Advanced Distributed Learning, 2010. [Online] available at: www.adlnet.gov/help/Pages/CommonQuestions.aspx.

[18] M. Tadlaoui, A. Chikh, K. Bouamrane: Alem: A reference model for educational adaptive web applications. in Intelligent and Adaptive Educational-Learning Systems, Springer, pp. 25-48. (2013).

[19] M. Tmimi, M. Benslimane, M. Berrada, K. Ouazzani: Implemented and Tested Conception Proposal of Adaptation Model for Adaptive Hypermedia. iJET Vol. 14, No. 2 (2019) 